\title{
A publicização da política: estratégias argumentativas de Dilma Rousseff contra o impeachment
}

\author{
Policy publicness: argumentative strategies of Dilma Rousseff \\ against impeachment
}

\section{Rejane de Oliveira Pozobon Andressa Dembogurski Ribeiro}

\section{Resumo}

Este estudo busca, através de uma breve revisão bibliográfica, aproximar o conceito de publicização (CASAQUI, 2004, 2005, 2009, 2011, 2014; ROMEYER, 2015) utilizado no campo organizacional e da saúde ao campo político. Para exemplificarmos esta aproximação, analisaremos, através da teoria da argumentação (BRETON, 2003), os pronunciamentos da presidenta Dilma Rousseff pré e pós votação da abertura do processo de impeachment na Câmara dos Deputados, que foram veiculados na rede social digital Facebook. Percebemos que, ao se adaptar à lógica midiática, a política faz uso de estratégias argumentativas e incorpora a arte da representação e da encenação, ganhando características que não estavam presentes em momentos anteriores.

\section{Palavras-chave}

Publicização; Política; Dilma Rousseff; Impeachment.

\section{Abstract}

This study aims, through a brief literature review, to approach the concept of publicness (CASAQUI, 2004, 2005, 2009, 2011, 2014; ROMEYER, 2015) used in the organizational and health fields to the political field. To exemplify this approach, we will analyze, through the theory of argumentation (BRETON, 2003), the pronouncements of president Dilma Rousseff before and after the opening of the impeachment voting proceedings in the House of Representatives, which were broadcasted on the Facebook social online network. We realize that, to adapt to media logics, the politician makes use of argumentative strategies and incorporate the art of representation and staging, acquiring features that were not present in the previous times.

\section{Keywords}

Publicness; Policy; Dilma Rousseff; Impeachment. 


\section{Introdução}

O Brasil perpassa por uma crise política que tem gerado certa inquietaçáo na sociedade. O pedido de impeachment ${ }^{l}$ da presidenta da República, Dilma Rousseff, tem causado grandes manifestaçóes e vem sendo a pauta principal dos meios de comunicação. Aproveitamos este contexto para iniciar um debate sobre um objeto de estudo que está sendo mapeado em pesquisa de doutoramento.

Pretendemos entáo, em um primeiro momento, trazer uma breve revisão bibliográfica sobre os pensamentos de Vander Casaqui (2004, 2005, 2009, 2011, 2014) e Hélene Romeyer (2015) acercado conceito de publicização. A segunda etapa consiste em analisar o pronunciamento da presidenta Dilma Rousseff, ocorrido no dia 15 de abril de 2016, dois dias antes da votaçáo da abertura do processo de impeachment, e o que aconteceu no dia 18 de abril de 2016, um dia depois da votaçáo na Câmara dos Deputados, que resultou em 367 votos a favor e 137 contra a saída da presidenta do comando do país. Isto implicou na sequência do processo de impeachment que também foi votado e aprovado no Senado. Esta análise tem como objetivo aproximar e exemplificar os processos de publicizaçáo ao campo político. No terceiro e último item, traremos algumas consideraçôes sobre essa primeira imersão teórica e empírica da pesquisa.

\section{A publicização da Política}

A mutação das práticas publicitárias, ocasionada pelas diferentes maneiras de consumo midiático fez com que surgissem outras formas de conceituar o exercício de vender produtos e serviços. A partir do momento em que se entendeu que a propaganda vai além dessa venda e propaga ideias, não só através de anúncios, surgiu o conceito de publicizaçáo. $\mathrm{Na}$ sociedade de consumo, a publicidade se dissemina através da produção cultural contemporânea, como o cinema, o jornalismo, o esporte, e em espaços públicos e privados (CASAQUI, 2009).

A publicização, diferente da publicidade, potencializa um discurso não comercial, que divulga pensamentos e objetiva alguma reação do receptor. No campo político, por exemplo, a busca pelo voto, a aliança com partidos, etc. A expansão do conceito de publicidade se deu porque o discurso publicitário é municiador de atributos intangíveis, que dialogam com os interesses, necessidades, desejos e quereres dos indivíduos (CASAQUI, 2009).

\footnotetext{
${ }^{1}$ Impeachment é um termo de origem inglesa que significa impedimento, e é aplicado a um chefe de Estado para afastá-lo de seu cargo.
} 
Com a origem de uma nova conceituação, surgem questionamentos sobre sua utilizaçáo e legitimidade. São anos de formação acadêmica entendendo a publicidade e propaganda como meio de vender produtos e serviços. Seria então a publicização a nomenclatura que envolveria todos os processos de visibilidade tornados possíveis pela comunicação midiática? Trindade (2013), através de uma leitura crítica da noção de publicização, demonstra preocupação sobre a substituição dos termos publicidade e propaganda por publicização.

Existe em consonância com o sistema de mercado publicitário um sistema educacional formador de profissionais técnicos e no nível do ensino superior, portanto a formação em publicidade e propaganda parece designar não só mensagens, mas todo um campo dado em função dos fenômenos cuja semântica e pragmática discursiva se encerram em torno do escopo de significados dos termos publicidade e propaganda. $\mathrm{E}$ como ressignificar toda essa estrutura em um novo termo? Em que medidas essa nova denominação é necessária? (TRINDADE, 2013, p.5253).

A partir da revisão bibliográfica sobre o termo, é possível perceber que o objetivo não é a substituição, mas sim a ampliação conceitual de suas reflexóes. Assim, teríamos como nomear as práticas também compreendidas no fazer publicitário, mas que náo podem ser denominados puramente como publicidade. Inicialmente o pensamento sobre a publicização objetivava unificar e emancipar a reflexão científica sobre a abundância de conceitos advindos do mercado publicitário, que nomeiam o que se distingue dos formatos tradicionais da publicidade com estrangeirismos e associaçôes ao termo "marketing", como buzz marketing, content marketing, marketing de guerrilha, etc. (CASAQUI, 2014).

Covaleski (2010) utiliza o termo publicidade híbrida para nomear as mudanças das práticas publicitárias na contemporaneidade. $\mathrm{O}$ autor entende que a publicização possui uma proximidade com essa definição porque acontece uma "hibridação" de jogos enunciativos através da materialidade das estratégias de publicização. Sendo assim, os estudos sobre publicização procuram entender como acontece a produçáo dos processos comunicativos que tornam sujeitos em consumidores.

Casaqui (2014) comenta que os processos de publicização são condicionados por meios técnicos disponíveis e pelas formas de interlocução, interatividade e interação. Sendo assim, 
[...] observar as estratégias de publicização e a forma como incorporam e negociam com o espírito do tempo mediado pelas técnicas comunicacionais é perceber como se articulam as categorias propostas pelo mapa das mediaçóes de Martín-Barbero (2001), a saber: institucionalidade; tecnicidade; socialidade; ritualidade (CASAQUI, 2014, p. 354).

A partir disto, o autor trabalha com a hipótese de que a esfera produtiva que responde pelos métodos de visibilidade abrange os encadeamentos discursivos e as mutaçôes da retórica do capitalismo contemporâneo. É através da ótica dos discursos, que, apropriados às demandas da atualidade, acontecem os diálogos entre os interlocutores. Através deste pensamento, conseguimos vislumbrar melhor a aproximação dos processos de publicização aos processos de visibilidade na política. O discurso aqui comentado sofreu mutaçóes a partir das mudanças das práticas publicitárias que fez com que não só em momentos de campanha eleitoral a figura política se preocupasse em publicizar seus pensamentos e assim angariar eleitores. É por isso que Casaqui diz que "apontamos para um fenômeno social mais difuso e difícil de apreender em seus limites e fronteiras, que é a profusão da lógica publicitária para práticas sociais que ultrapassam a esfera de produção da publicidade" (CASAQUI, 2014, p. 357).

Casaqui (2014) em seus atuais pensamentos sobre a publicização procura aproximar o termo ao campo do empreendedorismo social. Nessa perspectiva, é possível entender que a publicização torna consumível uma ordem cultural onde a relação entre sujeitos e objetos é significada, narrativizada, enfim, é a lógica de uma sociedade de consumo que se faz perceber para além dos anunciantes. A partir destes estudos o autor introduz o termo metapublicizaçáo. Segundo ele, o campo do empreendedorismo social se "metapubliciza", pois o prefixo "meta" tem como um de seus significados a noção de "transcendência", sendo assim, a publicização de um campo que se produz pela disseminação de falar de seus agentes, seus divulgadores, e seus agenciadores. Seja classificada como metapublicização ou não, há um processo comunicacional complexo e importante, que se ampara da estética publicitária e da forma mercadoria, a serviço da construção do papel social de um conjunto de agentes.

A aplicação da noção de publicização tanto ao empreendedorismo social, como no campo político, se legitima a partir do processo de visibilidade que torna pública uma mercadoria, uma marca, uma instituição, através de estratégias de persuasão que instauram seu interlocutor como consumidor. "Consideramos, por meio da tese da sociedade do espetáculo de Debord (1997), o processo generalizado 
de mercadorização da cultura, e da emergência da forma mercadoria como grande paradigma da produçáo cultural, em sentido amplo" (CASAQUI, 2014, p. 358). Dessa forma, assim como o empreendedorismo social, os agentes políticos são igualados a mercadorias e objetivam se tornar desejáveis e atraentes, como se fossem marcas ao se inserirem em uma lógica competitiva.

Outros pensamentos sobre a publicizaçáo são difundidos pela pesquisadora Romeyer (2015), através de análises no campo da saúde. Os primeiros apontamentos da autora são de que o espaço público é evolutivo, uma vez que se inscreve histórica, cultural, econômica, social e politicamente em contextos que também estão em mutaçóes. É por essa razão que ela parte do princípio de que "o espaço público não existe, ou mais exatamente, de que se trata de um tipo-ideal, uma concepção intelectual útil para análise, mas não objetiva" (ROMEYER, 2015, p. 114). Para ela, o único elemento palpável é o processo de publicização, pois ela permite fugir das questôes espaciais e de uma visão normativa.

Neste sentindo, a autora lembra do pensamento de Habermas (1993) sobre o princípio burguês de publicidade, onde as questôes de interesse geral eram discutidas abertamente em praça pública pelos cidadãos fazendo uso público da razão. $\mathrm{O}$ espaço público era ligado à democracia como projeto político. Entendemos então que através da publicização acontecia a intermediação entre a sociedade civil e o Estado. Ela chama de "publicidade crítica", o processo que acontece através da publicização de informaçóes públicas, e pressupóe obter o conhecimento sobre o funcionamento do Estado, a fim de que este último possa ser examinado e criticado sob o olhar da opinião pública (ROMAYER, 2004).

Segundo Romeyer,

a utilização polissêmica da noção de espaço público alimenta estratégias e discursos promocionais. Dessa forma, às vezes, ele é utilizado para dar um 'aval' a uma tendência de legitimação. Nesse caso, o espaço público é normalmente associado à democracia (ROMEYER, 2015, p. 117).

Essa troca de informações entre personagens políticos e sociedade civil foi possibilitada tanto pela transparência do funcionamento das instâncias, quanto pela acessibilidade dessa informação e da liberdade de expressão. Romeyer (2015) acredita que este processo de publicização compóe-se de duas fases distintas, mas, indissociáveis: visibilidade e colocação em debate, e esses dois elementos são metodologicamente mensuráveis. 
124 | Rejane de Oliveira Pozobon e Andressa Dembogurski Ribeiro

A partir deste breve apanhado teórico sobre a publicização, no próximo item traremos dois discursos da presidenta Dilma Rousseff para exemplificar, através da teoria da argumentação, proposta por Breton (2003), o uso deste conceito ao campo político.

\section{Teoria da argumentação: conceito e aplicabilidade}

A teoria da argumentação, aplicada ao campo da comunicação, será utilizada aqui como método de análise para a exemplificação da aproximação da publicização ao campo político. Tendo em vista que o objetivo deste artigo náo é o aprofundamento desta metodologia, a conceituação será breve, e as categorias de análise serão adaptadas.

A retórica é a fonte inicial do pensamento sobre a argumentação, e ela perpassa diversos campos de estudo nas ciências sociais. Na comunicação ela tem como objetivo, segundo Breton (2003), a adoção de determinado comportamento ou o compartilhamento de determinada opiniáo, por uma ou diversas pessoas. Conforme o autor, argumentar é comunicar, e por isso existe uma situação que exige a existência de parceiros e de uma mensagem. Além disso, o processo de argumentação não tem como finalidade convencer a qualquer custo, mas sim propor uma opinião justificando as razóes para ser aderida.

Breton (2003) acredita que as técnicas de comunicação do século XX desviaram do exercício de uma argumentação cidadã, e por isso se faz cada vez mais necessário uma reflexão sobre as condiçôes da expressão argumentativa. A manipulação da palavra e das consciências, que segundo ele, são resultados de alguns métodos antigos da retórica. Estes acontecem através do poder da mídia, dos artifícios de desinformação, e da publicidade, são os culpados por nos obrigarem a pensar a argumentação de uma forma oposta à retórica e à manipulaçáo. Se tratando mais especificamente da propaganda, o autor afirma que ela, amplamente empregada ao longo do século XX, sustenta-se em métodos sistemáticos para coagir as massas. 


\begin{abstract}
$\mathrm{Na}$ nossa sociedade de hoje, uma parte importante das estratégias para convencer colocadas em prática por nossos contemporâneos têm outras dominantes diferentes da argumentação. A publicidade, assim como a comunicação política, são bons exemplos disto. Fala-se, entâo, tanto de uma situação existente quanto de um potencial. $O$ estudo da argumentação é raramente separável de um interesse pela democracia e, de uma maneira mais geral, de um interesse por tudo o que vira apoiar a ideia que um livre debate entre os homens é possível e desejável. Argumentar é também contribuir para construir, de certa maneira, um mundo no qual, quando se trata de defender uma opinião, a razáo prevaleceria sobre as paixóes ou a estética sem, no entanto, negá-las (BRETON, 2003, p. 56).
\end{abstract}

A escolha da teoria da argumentação como método de análise dos objetos de estudo deste artigo se deu justamente por ser um ato que visa modificar o contexto de recepção, ou seja, as opiniốes do público, e isto é característica primária dos atores políticos em busca de seguidores. Sendo assim, Breton (2003) afirma que a formulação argumentativa deve levar em conta que aceitar a opinião proposta pelo outro tem consequências sobre o que se pensava anteriormente. Por não se tratar apenas de um processo informativo, "[...] o público, após o ato argumentativo, náo dispóe simplesmente de uma opinião 'a mais' sobre o que ele pensava, mas precisa mudar seu ponto de vista ou até sua visão de mundo, ao menos partes desta visão que estão ligadas ao argumento representado" (BRETON, 2003, p. 34). As estratégias de publicização no campo político são disseminadas, muitas vezes, através destes processos argumentativos, mas Breton (2003) alerta que as estratégias de sedução que podem estar inclusas nesta publicização, e que são tão frequentes na comunicação política, são argumentação se forem utilizadas apenas como apoio ilustrativo de um argumento, sem que o apelo sentimental seja o meio principal de disseminação da opinião.

Para tentar entender como a publicização ocorre através de processos argumentativos, é que analisaremos dois pronunciamentos da presidenta do Brasil, Dilma Rousseff. A crise política que toma conta do país, e que a partir de 2015 vem sendo mais divulgada mídia, fez com que o pedido para a abertura do processo de impeachment da presidenta fosse votado na Câmara dos Deputados no dia 17 de abril de 2016. A partir de acusaçôes dos partidos de Direita, contra o governo Dilma, a presidenta utilizou algumas estratégias em defesa do seu mandato. Uma delas foi o pronunciamento ocorrido no dia 15 de abril de 2016, dois dias antes da votação dos 
Deputados. Este pronunciamento foi feito através de um vídeo com 06min e 39s, no qual na imagem ${ }^{2}$, em plano médio, com o fundo do cenário desfocado, mas que aparentava ser uma sala de estar, Dilma veste um blazer bege e parece estar sentada. $\mathrm{O}$ objetivo da fala, que foi divulgada na página ${ }^{3}$ da presidenta no Facebook, é pedir o apoio do povo brasileiro na luta contra a abertura do processo de impeachment. O segundo material analisado antecede a coletiva de imprensa ocorrida no dia 18 de abril de 2016, um dia após a votação que resultou em 367 votos a favor e 137 contra dar sequência à ação de afastamento da presidenta do seu cargo. $\mathrm{O}$ vídeo que dura 19 min e 10 s, foi gravado no Palácio do Planalto, e teve sua transmissão na integra pelo dispositivo "ao vivo" da página ${ }^{4}$ do Palácio do Planalto no Facebook, e alguns dos seus trechos replicados na mídia de massa. Neste pronunciamento, Dilma estava vestida de azul, fez seu discurso atrás do púlpito, com a bandeira do Brasil e o painel com a logomarca de seu governo ao fundo, e tudo foi gravado em plano aberto. Desta vez, o objetivo era, além de seguir na busca por apoio dos eleitores, mostrar que, apesar da votaçáo contra o seu mandato, a luta ainda não tinha sido vencida e que nada a faria desistir de presidir o país até os últimos dias do seu mandato em 2018.

Breton (2013) comenta que estas situações de comunicação, em que o objetivo é convencer, são sempre complexas e que as realidades humanas são inseparáveis deste processo. Por isso, segundo o autor, nestes casos em que o ser humano é um objeto incompreensível para as ciências exatas, é praticamente impossível a existência de "argumentos puros". O autor ainda se questiona se por esse motivo nenhuma análise seria entáo possível, e relata que,

Evidentemente que não, pois há sempre, ou quase sempre, dominantes que nos levam a dizer que se trata de um argumento ou de uma comparação. Além disso, toda a riqueza da interpretação vem justamente do fato de haver várias interpretaçóes possíveis. Enfim, podemos constatar que se certos argumentos são próximos uns dos outros, a ponto de confundirem-se às vezes, existem grandes famílias de argumentos que se distinguem pela natureza do raciocínio que eles utilizam (BRETON, 2003, p. 63).

\footnotetext{
2 Temos noção de que a análise de imagem será breve e superficial, apenas temos como objetivo mostrar as diferenças semióticas dos dois pronunciamentos analisados.

${ }^{3}$ ROUSSEFF, 2016a.

${ }^{4}$ ROUSSEFF, 2016b.
} 
Intuímos então que estes processos comunicacionais utilizados pela presidenta Dilma Rousseff, nestes dois pronunciamentos que analisaremos, são inseparáveis das realidades humanas e entendemos que "a dinâmica da construção e recepção dessas questóes públicas não pode, no entanto, ser restituída unicamente por uma análise de conteúdos midiáticos" (ROMEYER, 2015, p. 126). Pois, conforme ainda comenta Romeyer (2015), todo o trabalho de temporalização e de contextualização político, econômico e social, de atores coletivos e individuais faz parte destas questóes públicas, e acreditamos também fazerem parte dos processos argumentativos.

\section{A fala da presidenta: Análise dos argumentos acionados}

Breton (2003) propóe entendermos o discurso por meio de elementos argumentativos. Para dar conta da análise proposta neste artigo, utilizaremos algumas das categorias de análise propostas pelo autor. São elas: autoridade (que pode ocorrer através da competência, da experiência e do testemunho); valores comuns e pontos de vista e reenquadramento.

$\mathrm{O}$ argumento pela autoridade, como a própria nomenclatura conclui, acontece através de alguém que tem a autoridade para fazê-lo. Esta autoridade, obviamente, deve ser aceita pelo público para que ele possa receber como verdadeiro o que é proposto. Conforme Breton (2003) dois casos são possíveis: “[...] ou o orador apoia o enquadramento do real sobre sua própria autoridade, ou ele convoca uma autoridade exterior" (BRETON, 2003, p. 77). Acontece ainda de o argumentador utilizar aspectos pouco conhecidos de autoridade do próprio auditório para fazê-lo aceitar uma opinião. $\mathrm{O}$ argumento pela autoridade é subdividido em competência, experiência e testemunho.

O argumento de "autoridade por competência" julga que existe uma competência científica, técnica, moral ou profissional que vai validar este argumento. No primeiro pronunciamento da presidenta Dilma Rousseff é possível exemplificá-lo através das seguintes falas:

O Brasil vive um momento que será decisivo para o nosso futuro. (0:02) / Por isso, é minha obrigação esclarecer os fatos e denunciar os riscos dessa aventura golpista para o país. (0:42) / Os derrotados mergulharam o país num estado permanente de instabilidade política, impedindo a recuperaçáo da economia... (1:05) / O Brasil e a democracia náo merecem tamanha farsa. (2:07) / Nenhum governo será legítimo se não nascer do voto popular, livre, direto, universal e secreto (4:06) (ROUSSEFF, 2016a). 
No segundo pronunciamento é visível nos trechos abaixo:

[...] injustiçada porque considero este processo, é um processo, e não tem base de sustentação, e é por isso que me sinto injustiçada. (0:30) / ...assisti ao longo da noite de ontem todas as intervençóes e não vi uma discussão sobre o crime de responsabilidade, que á única maneira de se julgar um Presidente da República no Brasil, isso porque a constituiçāo assim o prevê. (01:20) / A constituição prevê que o impeachment é possível sim, e temos de reconhecer que está lá escrito, mas ao mesmo tempo, a constituição estipula que é necessário a existência do crime de responsabilidade para que uma pessoa possa ser considerada e afastada do cargo de Presidente da República depois de receber os votos majoritários da populaçáo. (01:47) / os atos que me acusaram foram baseados em pareceres técnicos e nenhum deles beneficia a mim pessoalmente. (03:45) / sấo atos que são praticados por todos os Presidentes da República no exercício do seu cargo. (04:10) / Quando um Presidente pratica atos administrativos ele faz baseado em toda uma cadeia de decisão. Essa cadeia de decisão implica em pareceres técnicos, em análises, avaliações jurídicas, a partir daí o Presidente assina (04:20) (ROUSSEFF, 2016b).

$\mathrm{O}$ argumento de autoridade por competência foi utilizada por Dilma Rousseff nos âmbitos da técnica moral ou profissional. Quando ela fala em uso da constituição e também comenta sobre processos da prática da presidência, ela está tomando posse de uma autoridade através do cargo que ocupa. E reafirma-se aqui que argumentar é mais do que puramente conceber um argumento, mas sim, comunicar, dirigir-se ao público e convencê-lo a partilhar uma opiniáo (BRETON, 2003).

$\mathrm{O}$ argumento de autoridade por experiência “[...] é menos baseado em uma competência, suspeita de ser teórica, do que em uma prática efetiva no domínio em que o orador se exprime" (BRETON, 2003, p. 82). Isto fica visível quando a presidenta, no primeiro pronunciamento, diz "desde que fui eleita, parte da oposição, inconformada, pediu a recontagem dos votos, tentou anular as eleiçóes, e passou a conspirar pelo impeachment (0:52)" (ROUSSEFF, 2016a).

E quando, no segundo pronunciamento, ela fala: 


\begin{abstract}
Ora eu recebi 54 milhóes de votos e me sinto indignada com a decisão que recepcionou a questão da apreciação da adminicibilidade do meu impeachment. (02:20) / ...os atos pelos quais eles me acusam foram praticados por outros Presidentes da República antes de mim, e não se caracterizaram como sendo atos ilegais ou atos criminosos, foram considerados legais. (03:04) / ...eu sempre lutei pela democracia, [...] e vou continuar lutando por ela. (12:13) / ... e isso quem me ensinou foi a história do meu país (17:08) (ROUSSEFF, 2016b).
\end{abstract}

Neste caso, a experiência vivida pela presidenta é representada argumentativamente para mostrar que ela tem passado por situaçóes parecidas e que tem conhecimento para enfrenta-las. O argumento de "autoridade por testemunho" acontece através da presença do argumentador em uma manifestação, um acontecimento etc. “[...] o testemunho de um fato terá mais peso para propor seu enquadramento em uma perspectiva argumentativa" (BRETON, 2003, p. 83). Isto pode ser exemplificado nos seguintes trechos do segundo pronunciamento:

Eu no passado, na minha juventude, enfrentei por convicção a ditadura. E agora eu também enfrento por convicção um golpe de estado. Um golpe de estado que não é o tradicional da minha juventude, mas infelizmente é o golpe tradicional da minha maturidade. (12:20) / Aliás, eu comecei lutando numa época que era muito difícil lutar. Era a época da ditadura aberta e escancarada. Aquela que te torturava fisicamente e que matava, e que tirava a vida de pessoas companheiros teus $(16: 20)$ (ROUSSEFF, 2016b).

Dilma, nestes trechos de argumentação por testemunho, utilizou sua história de vida para comentar sobre os acontecimentos do presente e talvez do futuro. Neste caso, os sentimentos se misturam no processo argumentativo e comprovam o pensamento de Breton (2003) de que é impossível a existência de "argumentos puros".

Geralmente o argumento por autoridade se insere em um conjunto argumentativo e serve para preencher vazios, para construir "pontes", e isto serve para justificar a sua importância, pois neste tipo de argumento podem ocultar-se diversos pontos de vista. (BRETON, 2003).

Outros tipos de argumentos propostos por Breton (2003) são os valores e pontos de vista. $\mathrm{O}$ autor afirma que os valores comuns compóem um apoio efetivo 
para desenvolver uma argumentação, e que a sua lembrança é em si mesma um argumento que possui mais força do que a realidade.

Lembremos simplesmente de algumas grandes linhas. A Antiguidade grega distingue três valores essenciais, o verdadeiro, o belo e o bem, que são os ideais que o homem deve buscar, mas que são ao mesmo tempo normas argumentativas. Uma opinião será considerada verossímil e terá força de convicção se for congruente com uma ou outra conjugação destes valores (BRETON, 2003, p. 86).

Já a existência e a utilização da argumentação através dos pontos de vista mostra que eles se tornaram possíveis "[...] pela crença unanimemente partilhada de que o mundo, o universo simbólico no qual evoluímos, é dotado de uma certa ordem e que esta ordem pode ser, ao menos parcialmente, conhecida" (BRETON, 2003, p. 93). $\mathrm{O}$ autor acredita que os pontos de vista da argumentação podem ser ferramentas de conhecimento, pois eles contribuem para a construção das referências partilhadas pelos parceiros de uma comunicação.

Os valores e pontos de vista são percebidos no primeiro pronunciamento de Dilma através das falas expostas a seguir:

O que está em jogo é o respeito à vontade soberana do povo brasileiro, o respeito às urnas. (0:32) / O que está em jogo são as conquistas sociais e os direitos dos brasileiros. (0:37) / Para alcançar os seus objetivos, estão dispostos a violentar a democracia e a rasgar a Constituição, espalhando a intolerância, o ódio, e a violência entre nós. (3:14) / Não se trata de concordar ou náo com o governo, mas de combater um golpe de estado, uma violação constitucional, que poderá mergulhar o Brasil em um doloroso processo de instabilidade e insegurança. (3:54) /...todos nós, cidadãos e cidadãs deste país, somos os guardiōes dos valores que fazem do Brasil esta grande nação (06:20) (ROUSSEFF, 2016a).

No segundo pronunciamento eles aparecem nos seguintes trechos: 
A injustiça sempre ocorre quando se esmaga o processo de defesa, mas também, quando de uma forma absurda, se acusa alguém por algo, primeiro que não é crime, e segundo acusa e ninguém se refere a qual é o problema. (0:50) / ...tenho a consciência tranquila, eu não os fiz ilegalmente, não os fiz baseado em nenhuma ilegalidade. (05:05) / ... não há contra mim nenhuma acusação de desvio de dinheiro público, não há contra mim acusação de enriquecimento ilícito, eu não fui acusada de ter contas no exterior. (05:27) / ... me sinto injustiçada por não permitirem que eu tenha nos últimos quinze meses governado num clima de estabilidade política. $(06: 10)$ / Uma sensação de que já uma violência no Brasil, contra a verdade, contra a democracia, e contra o estado democrático de direito. (08:50). I ...se é possível condenar um Presidente da República sem que ele tenha qualquer culpabilidade, o que é possível de ser feito com o cidadão qualquer? (09:34) / ...é estarrecedor que um vice-presidente no exercício do seu mandato conspire contra a Presidente (14:50) (ROUSSEFF, 2016b).

A presidenta utiliza termos como: respeito, justiça, ódio, violência etc. em que se pode identificar a argumentação através dos valores comuns da população. Em alguns momentos ela entende que estes valores estão sendo obstruídos pela oposição. Breton (2003) já comentava que argumentar é escolher em uma opinião os aspectos que a tornarão aceitável para um dado público. "A transformação de uma opinião em argumento em função de um auditório particular é precisamente o objeto da argumentaçáo" (BRETON, 2003, p. 32). Então se tratando dos seus pontos de vista ela escolhe opiniôes para se defende das acusaçóes e ao mesmo tempo publiciza suas ideias do que seria um governo correto.

Como já comentado, o objetivo de um argumento é modificar o contexto de recepção do público para depois introduzir uma opinião. Sendo assim, nas situações em que a argumentaçáo através dos valores, dos pontos de vista, e da autoridade, alude à retomada de um mundo conhecido e serve de referência para o público, o reenquadramento sugere uma novidade, um deslocamento, um outro olhar sobre o acontecimento. $\mathrm{O}$ reenquadramento então, não enfrenta o problema, e sim o aborda de outra maneira (BRETON, 2003). Este processo argumentativo apresenta uma novidade para o público. "Eles o colocam em um mundo no qual, espontaneamente o auditório não pensara e onde seus pontos de referência habituais não funcionam, mesmo que os 'elementos' que compóem este novo mundo lhe sejam conhecidos separadamente” (BRETON, 2003, p. 95). 
Dilma Rousseff reenquadra o assunto do primeiro pronunciamento através das seguintes falas:

No próximo domingo teremos uma oportunidade de reafirmar, mais uma vez, o nosso compromisso histórico com a democracia, a liberdade e o estado de direito. (0:07) / Brasileiros e brasileiras nosso país tem todas as condiçóes de sair da crise. De retomar o crescimento econômico, com emprego, estabilidade, distribuiçáo de renda, e oportunidade para todos (05:31) (ROUSSEFF, 2016a).

No segundo pronunciamento o reenquadramento acontece por meio dos seguintes trechos:

Eu acredito que é muito ruim para o Brasil que o mundo veja que a nossa jovem democracia enfrenta um processo com essa baixa qualidade. (09:10) / ...não se pode chamar de impeachment o que é a tentativa de uma eleição indireta. (13:50) / Mas eu tenho força, ânimo e coragem. Eu não vou me abater, eu não vou deixar paralisar por isso. Eu vou continuar lutando, como fiz ao longo de toda a minha vida. (16:00) / De uma certa forma eu estou tento meus sonhos torturados, meu direito torturado. Agora, não vão matar em mim a esperança, porque eu sei que a democracia é sempre o lado certo da história. (16:52) / Não é por mim, mas é pelos 54 milhóes de votos que eu tive, mas além disso é uma luta de todos os brasileiros, mesmo daqueles que criticam o meu governo ou não o apoiam. (18:20) / Uma luta pela democracia do nosso país, sem democracia não haverá crescimento econômico, sem democracia não há e nem haverá a capacidade da gente retomar o crescimento, criar emprego, e continuar com as políticas de inclusão social... (18:35) / A democracia será sempre o lado certo da história (19:05) (ROUSSEFF, 2016b).

Percebemos através desta análise que o reenquadramento é o argumento que mais publiciza as ideias de governo da presidenta Dilma. É neste momento que ela muda o foco do seu discurso e propóe pensarmos, não mais no processo de impeachment, mas sim em sua força e coragem para liderar o país. Quando ela diz, por exemplo, que é "uma luta pela democracia do nosso país, sem democracia náo haverá crescimento econômico, sem democracia não há e nem haverá a capacidade da gente retomar o crescimento, criar emprego, e continuar com as políticas de inclusão social...” (18:35) (ROUSSEFF, 2016b), ela está reenquadrando a luta contra o impeachment para uma luta pela democracia. 
Breton (2003) afirma que a modificação do contexto de recepção para que aconteça o processo de argumentação ocorre em duas etapas, e que elas são ao mesmo tempo indispensáveis uma à outra e obrigatoriamente sucessivas. Conforme o autor, primeiro se "enquadra", em seguida se "liga". A primeira etapa constrói um real comum ao orador e ao auditório, no segundo momento se constrói um vinculo entre este acordo e a opiniáo proposta. Ele chama isto de "duplo gatilho" argumentativo. "Dirigimo-nos aos outros, primeiramente para que eles mudem sua visão das coisas, em seguida, para lhes mostrar que a nova opinião proposta está de acordo com esta nova visão das coisas" (BRETON, 2003, p. 67).

Breton (2003) comenta ainda que a propaganda nas formas extremamente sofisticadas que lhe foram dadas no século XX - o que nos entendemos e conceituamos aqui como publicização - continua sendo o modelo de referência da manipulação da relação emissor/receptor com o objetivo de fazer como que as opinióes sejam aceitas a qualquer custo. "A propaganda reside essencialmente na manipulação psicológica do auditório, usando também meios de coerção física, a fim de condicioná-lo a receber uma opinião dada” (BRETON, 2003, p. 51).

Unindo os pensamentos de Casaqui (2004, 2005, 2009, 2011, 2014), Romeyer (2015) e Breton (2003), concluímos que a publicização da política muitas vezes é feita através da argumentação. Os atores políticos precisam, ao publicizarem suas ideias, fazer com que o "duplo gatilho" argumentativo ocorra e que o público acolha suas opinióes. Percebemos também que a publicização política talvez seja a publicização em sua forma mais genuína, pois ela perpassa a divulgação de atributos intangíveis e confirma o pensamento de Casaqui (2009) de que esses atributos dialogam com os interesses, necessidades, desejos, quereres dos indivíduos.

Após este breve estudo, reafirmamos também de que a publicização política náo acontece só em período de campanha eleitoral. Com as mudanças sociais comentadas no início deste artigo, o campo político, assim como o campo publicitário, foi afetado e precisou de uma reconfiguração das suas práticas comunicacionais.

\section{Considerações Finais}

A proposta deste artigo foi fazer uma primeira imersão no conceito de publicização (CASAQUI, 2004, 2005, 2009, 2011 e 2014; ROMEYER, 2015), e testar a aplicabilidade da teoria da argumentaçáa (BRETON, 2003) como metodologia de análise de discursos políticos. 
Para tanto, trouxemos em um primeiro momento uma breve explanação sobre o conceito de publicização e buscamos aproximá-lo do campo político. A teoria $\mathrm{da}$ argumentaçáo foi abordada em um segundo momento e fundamentou nossa análise empírica. $\mathrm{Na}$ terceira parte, através das categorias de análise escolhidas, comprovamos que a argumentação é parte fundamental do processo de publicização política. Isto vai ao encontro do pensamento de Breton (2003) que afirma que "[...] a publicidade moderna, objeto complexo, deve sua temível eficiência ao fato de trabalhar ao mesmo tempo com todos os registros do ato de convencer".

Percebemos o forte caráter persuasivo dos discursos analisados, não no sentido de trazer uma abordagem explicativa de convencimento, mas o apelo a outras instâncias de adesáo, como a experiência e o testemunho. É neste sentido que os resultados aqui expostos nos levam a partilhar do pensamento de Charaudeau (2008, p. 46), no qual o autor afirma que "talvez seja mesmo necessário de crer que são as ideias que governam o mundo e precisar que apenas valem pela maneira como são transmitidas de uns para outros, pela maneira como circulam entre os grupos e como influenciam uns e outros".

No entanto, não há política sem discurso. Não é possível estudarmos e entendermos a política sem analisarmos os discursos que nascem e circulam neste campo. Nas palavras de Charaudeau (2008, p. 39) "a ação política e o discurso político estáo indissociavelmente ligados, o que justifica pelo mesmo raciocínio o estudo político pelo discurso".

Reafirmamos que este estudo é demasiadamente importante e não pode se resumir apenas aos pensamentos propostos aqui. Este é o princípio de um estudo que objetiva entender como acontecem todos os processos sociais que envolvem a comunicação política e a publicização em um novo contexto histórico social. 
Rejane de Oliveira Pozobon é Doutora pelo Programa de Pós Graduação em Comunicação da Universidade do Vale do Rio dos Sinos (UNISINOS). Professora do Programa de Pós Graduação em Comunicação da Universidade Federal de Santa Maria (UFSM). E-mail: rejane.op@terra.com.br.

Andressa Dembogurski Ribeiro é Doutoranda no Programa de Pós Graduação em Comunicação da UFSM. E-mail: andressadembo@gmail.com.

\section{Referências}

BRETON, Philippe. A argumentação na Comunicação. Bauru: EDUSC, 2003.

CASAQUI, Vander. Ethos Publicitário: as estratégias comunicacionais do capital financeiro na negociação simbólica com seu público-alvo. 2004. 503f. Tese. (Doutorado em Comunicação) - Escola de Comunicação e Artes, Universidade de São Paulo, São Paulo. 2004.

CASAQUI, Vander. A Publicidade das Instituições Bancárias em Situação de Conflito com seu Público Alvo. In: Anais do XXVIII CONGRESSO BRASILEIRO DE CIÊNCIAS DA COMUNICAÇÃO, 2005. Rio de Janeiro: 2005.

CASAQUI, Vander. A esfera simbólica da produção: estratégias de publicização do mundo do trabalho na mídia digital. Revista Rumores, São Paulo, v. 3, n. 6, p. 1-11, 2009.

CASAQUI, Vander. Por uma teoria da publicização: transformaçóes no processo publicitário. Significaçâo: revista de cultura audiovisual, São Paulo, v. 38, n. 36, p. 131 - 152. 2011.

CASAQUI, Vander. Metapublicização de um novo (mesmo) mundo: empreendedorismo social, entre a utopia e a forma mercadoria. In: PEREZ, Clotilde; TRINDADE, Eneus. (orgs.). O sistema publicitário e a semiose ilimitada. São Paulo: INMOD/ABP2/PPGCOM-ECA-USP, 2014. p. 351 366.

CHARAUdeAU, Patrick. Discurso Político. São Paulo: Contexto, 2008.

COVALESKI, Rogério. Publicidade híbrida. Curitiba: Maxi Editora, 2010.

ROMEYER, Hèléne. Do espaço público ao processo de publicização: o caso das questôes da saúde. In:

CASTRO, Paulo César. (Org.). Dicotomia público/privado: estamos no caminho certo? Maceió: EDUFAL, 2015, p. 113 - 138.

ROUSSEFF, Dilma. Em defesa da Democracia: pronunciamento. [15 de abril, 2016a]. Brasília: vídeo online. Disponível em: <https://www.facebook.com/DilmaRousseff/videos/1103991776321079/>. Acesso em: 10 mai., 2016.

ROUSSEFF, Dilma. Coletiva de Imprensa com a presidenta Dilma: coletiva de imprensa. [18 de abril, 2016b]. Brasília: vídeo online. Disponível em: 
136 | Rejane de Oliveira Pozobon e Andressa Dembogurski Ribeiro

<https://www.facebook.com/DilmaRousseff/videos/1105630322823891/>. Acesso em: 12 mai. 2016.

TRINDADE, Eneus. Alcance de sentidos dos termos publicidade e propaganda em contextos demediatização. In: PEREZ, Clotilde; TRINDADE, Eneus. (Orgs.). Por uma publicidade livre sempre. São Paulo: INMOD/ABP2/PPGCOM-ECA-USP, 2013, p. 48-54.

Texto recebido em 08 de fevereiro de 2017. Aprovado em 24 de março de 2017. 